\title{
Novel MEF2C point mutations in Chinese patients with Rett (-like) syndrome or non- syndromic intellectual disability: insights into genotype-phenotype correlation
}

\author{
Jiaping Wang ${ }^{1}$, Qingping Zhang ${ }^{1}$, Yan Chen ${ }^{1}$, Shujie Yu², Xiru Wu ${ }^{1}$, Xinhua Bao ${ }^{1 *}$ (D) and Yongxin Wen
}

\begin{abstract}
Background: MEF2C (Myocyte-specific enhancer factor 2C) has been associated with neurodevelopmental disorders. This study aimed at delineating the clinical profiles of MEF2C gene mutations.

Methods: In total, 112 Chinese patients with intellectual disability (ID) were recruited, including 44 patients presented with Rett syndrome (RTT) or RTT-like syndrome, and 68 patients with non-syndromic ID. Targeted nextgeneration sequencing (NGS) was performed. Detailed clinical information was collected.

Results: Five heterozygous MEF2C gene mutations were identified, of which three were novel. The MEF2C mutant rate was $4.5 \%(5 / 112)$ in total, and 6.8\% (3/44) in the RTT (-like) cohort. All patients with MEF2C gene mutation presented with cognitive impairment, gross motor delay, speech disorder and autistic features. Four patients had epilepsy, which responded well to antiepileptic drugs. One female was diagnosed with classical RT, two females with RTT-like syndrome, and two males with non-syndromic ID. Generally, the phenotype of two males with relatively downstream mutations (c.565C > T, p.Arg 189*; c.766C > T, p.Arg 256*) was milder than that of three females with upstream mutations (c.48C > G, p.Asn16Lys; c.334G > T, p.Glu112* and c.403-1G > T).

Conclusions: Our findings expanded the current understanding of the consequences of MEF2C dysfunctions, especially MEF2C point mutations. MEF2C mutations are associated with a broad clinical spectrum, ranged from classical RTT to non-syndromic ID. Through our study, it can be inferred that there is correlation between the phenotype and MEF2C-genotype, the mutation site. Overall, the MEF2C gene mutational analysis should be performed in ID cohort, especially in patients with features overlapped with RTT.
\end{abstract}

Keywords: MEF2C, Rett (-like) syndrome, Non-syndromic intellectual disability, Genotype-phenotype correlation

\section{Background}

$M E F 2 C$ (Myocyte-specific enhancer factor 2C), a member of MEF2 subfamily, is a transcriptional activator binding specifically to the MEF2 element, which has pivotal role in myogenesis, hematopoiesis, neurogenesis and synaptogenesis $[1,2]$. Especially, $M E F 2 C$ is crucial for normal neuronal development, distribution, and electrical activity in the neocortex [3]. MEF2C haploinsufficiency caused by either large deletions encompassing
$M E F 2 C$, or intragenic mutations of $M E F 2 C$, is associated with neurodevelopmental disorders [4].

In this study, we performed targeted next-generation sequencing (NGS) in Chinese patients with intellectual disability (ID) of unknown causes. $M E F 2 C$ mutations were identified in five patients, including three females with RTT or RTT-like features, and two males with non-syndromic ID. The phenotypes and genotype of $M E F 2 C$ mutation in Chinese ID patients were reported here.

\footnotetext{
* Correspondence: zwhang@pku.eud.cn

${ }^{1}$ Department of Pediatrics, Peking University First Hospital, No 1, Xi'anmen

Street, Xicheng District, Beijing 100034, China

Full list of author information is available at the end of the article
}

(c) The Author(s). 2018 Open Access This article is distributed under the terms of the Creative Commons Attribution 4.0 International License (http://creativecommons.org/licenses/by/4.0/), which permits unrestricted use, distribution, and reproduction in any medium, provided you give appropriate credit to the original author(s) and the source, provide a link to the Creative Commons license, and indicate if changes were made. The Creative Commons Public Domain Dedication waiver (http://creativecommons.org/publicdomain/zero/1.0/) applies to the data made available in this article, unless otherwise stated. 


\section{Methods \\ Patients}

In total, 112 Chinese patients with ID were enrolled into this study from August 2015 to March 2018, including 68 females and 44 males, aged from 13 months to 12.5 years. Among them, 25 girls were initially diagnosed with RTT (21 with typical RTT, 2 with Han-RTT, 1 with Zappella variant of RTT and 1 with congenital RTT), 16 females and 3 males with RTT-like syndrome. Mutations in MECP2, CDKL5 and FOXG1 have been ruled out in the patients of RTT (-like) cohort. The other 68 patients presented with non-syndromic ID. Metabolic or mitochondrial disorders, central nervous system infection or other known etiologies were excluded.

Detailed clinical information including clinical manifestation, electroencephalogram (EEG), magnetic resonance imaging (MRI), and family history, etc., was collected. Genomic DNA was extracted from peripheral leukocytes of the patients and their parents. This study was approved by the Medical Ethics Committee, Peking University First Hospital. Written informed consent was obtained from the parents of the patients.

\section{Targeted next-generation sequencing}

A genetic panel which is related to ID was designed, containing 512 genes (supplemental material, Additional file 1: Table S1) in total. Especially, genes associated with RTT (-like) syndrome were included. Library preparation including end repair, adapter ligation and PCR enrichment were carried out as recommended by the NEBNext Rfast DNA Fragmentation and Library Prep Set for Ion Torrent. Targeted regions were captured with a customized SeqCap panel (Roche). The enriched libraries were sequenced on an Ion Torrent Proton sequencer with 200 bp single end read. Signal processing and base calling were carried out using Torrent Suite 5.04 software. Reads were aligned to the human reference genome build UCSC hg19 using Tmap. Variants were called using the variant caller from Torrent Suite.

Variants were annotated using ANNOVAR (http:// annovar.openbioinformatics.org/en/latest/), assessment of the variants were carried out following the ACMG guidence. Common sites with population allele frequency above 5\% according to dbSNP 138, 1000 Genome Project, esp6500si and ExAC databases were excluded. Rare loss-of-function variants were selected for follow-up analyses. Selected variants with depth lower that 20X and allelic fraction lower than 30\% were manually reviewed with IGV. Functional variants annotated by HGMD, Clinvar or predicted to be deleterious by SIFT and Polyphen 2 were regraded as candidates.

\section{Results}

Molecular analysis

Causative gene mutations were identified in 14 patients of our RTT (-like) cohort, with detection rate of $31.8 \%$ (14/44), incluing $3 M E F 2 C$ mutations. In the non-specific ID group, 9 patients $(13.2 \%, 9 / 68)$ were identified with pathogenic mutations, including 2 $M E F 2 C$ mutations. The wild type and mutant allele of $M E F 2 C$ is approximately at 1:1 (ranging from 39.1 to $47.2 \%)$, so mosaicism were not considered.

Five heterozygous mutations in $M E F 2 C$ were identified in three females with RTT (-like) syndrome and two males with non-syndromic ID. The MEF2C mutant rate was $4.5 \%(5 / 112)$ in total, whereas $6.8 \%(3 / 44)$ and $2.9 \%$ $(2 / 68)$ in Rett (-like) cohort and non-syndromic ID group, respectively. These five mutations included three nonsense mutations, one splicing site mutation, and one missense mutation. Three $M E F 2 C$ mutations (c. $48 \mathrm{C}>\mathrm{G}$, p.Asn16Lys; c.403-1G > T; c.766C > T, p.Arg256*) arose de novo, and the other two (c.565C > T, p.Arg189*; c.334G > T, p.Glu112*) were of unknown origin, as the parental DNA was not available. Among these mutations, two mutations, c.565C > T, p.Arg189* and c.766C > T, p.Arg256*, were reported pathogenic, the other three mutations, c.48C > G, p.Asn16Lys; c.334G > T, p.Glu112*; and c.403-1G > T, were novel. They were predicted as pathogenic by Mutationtaster, the missense mutations, c.48C > G, p.Asn16Lys, was predicted as pathogenic by PolyPhen-2 and SIFT as well. A schematic representation of the $M E F 2 C$ protein, including the mutations identified in this study as well as the mutations previously reported, is shown in Fig. 1.

\section{Clinical profiles of patients with MEF2C mutations}

Patient 1 is a girl aged 5 years and 9 months, the first child of a healthy nonconsanguineous couple. Her psychomotor milestones were profoundly delayed, with raising head at 8 months, sitting alone at 1 year old, and still unable to walk by herself at 5 years and 9 months. Poor eye contact, hand clapping, hand wringing and bruxism were observed at 1 year old, followed by deterioration of hand skills. Epileptic attack occurred at 20 months old, and she responded to valproate (VPA), oxcarbazepine (OXC), and topiramate (TPM) combined therapy. Seizure free was achieved at 5.5 years old. EEG demonstrated spike-slow waves at right medial and posterior temporal, with generalization. MRI (1 year old) revealed enlargement of frontal subarachnoid space. Above manifestations led to the diagnosis of typical RTT. However, mutational analysis of MECP2, CDKL5 and FOXG1 was negative. Through this study, a de novo missense $M E F 2 C$ mutation, c.48C > G, p.Asn16Lys, was identified, which was a novel mutation. 


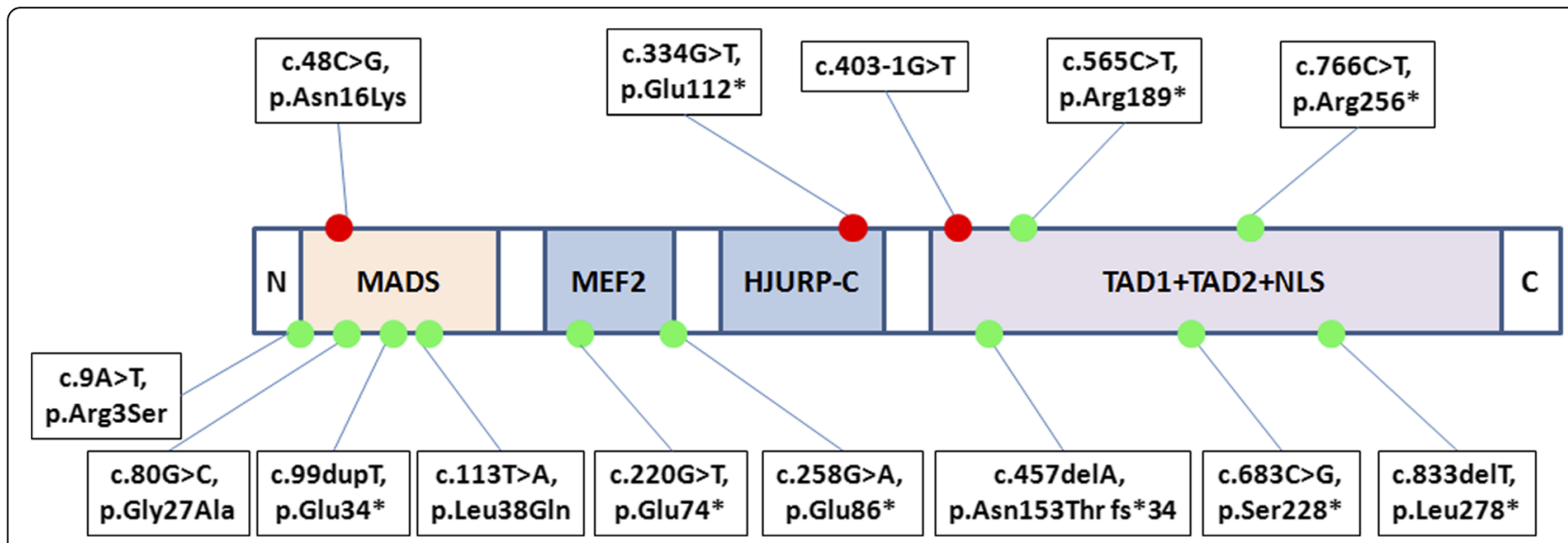

Fig. 1 The structure of the MEF2C protein and the location of MEF2C mutations. Red dots: Novel mutations found in this study. Green dots: Reported mutations. The upper line: Five MEF2C mutations identified in this study. The lower line: Nine MEF2C mutations that has been described previously. N, N-terminus; MADS, MCM1, agamous, deficiens, serum response factor; MEF2, myocyte enhancer factor 2; TAD, transcriptional activation domain; NLS, nuclear location signal; C, C-terminus

Patient 2 is a 2.5 years old girl presented with RTT-like ID. she displayed profound psychomotor retardation, with controlling head at 5 months, sitting alone at 8 months. She remained unable to walk independently and still had no speech at 2.5 years old. She developed stereotypic hand movements and bruxism at 2 years of age. No seizure was reported, but there was epileptiform discharge on EEG at age of 2 years. Brain MRI revealed high $T_{1}$ and $T_{2}$ signal at posterior horn of bilateral ventricle. A nonsense mutation, c. $565 C>\mathrm{T}$, p.Arg189*, of $M E F 2 C$ was discovered, a known disease causing mutation (https://www.ncbi.nlm.nih.gov/clinvar/).

Patient 3 is a 23-month-old girl who presented with RTT-like features. Feeding difficulties caused concern at 3 months of age. No epilepsy was observed, though she had medical history of febrile convulsions at 9 months old. There was significant delay in her developmental milestones, without obvious retrogression. She could sit alone at 1 year old, and walk at 23 months of age, with abnormal gaits. Unmeaningful language began at 12 months. She also presented with poor eye contact, stereotypic actions, breathing disturbance, and sleeping abnormalities. She suffered from recurrent respiratory infections frequently after 15 months of age. MRI revealed hypomyelination at 1 year and 10 months of age. A novel nonsense mutation, c.334G > T, p.Glu112*, in $M E F 2 C$ was identified.

Patient 4 was a boy aged 7 years and 8 months. He achieved the gross motor developmental milestones somewhat delay, with rising head at 1 year old, sitting alone at 1 year and 2 months, and walking at 1.5 years. Lack of speech was another problem, that he still cannot speak a single word so far (7 years and 8 months). He was always immersed in his own world, showed little interest to the others, and lacked eye-contact. Febrile seizures attacked at 1 year, which turned into afebrile seizures at 2 years old. Partial seizures occurred $1 \sim 2$ times per month, lasted few minutes to more than half an hour. The epilepsy was fever-sensitive. VPA was used at 2.5 years of age, and no seizures occurred after 4 years of age. EEG at 2.5 years displayed (multi-) spike and slow waves at right occipital region, with slow rhythm on the background. MRI at 3 years of age was normal. A novel mutation, c.403-1G > T, of $M E F 2 C$ was identified, which arose de novo.

Patient 5 was a boy of 6 years and 4 months. He presented with developmental delay, with rising head at 7 months, sitting alone at 1 year, and walking at 2 years old. Language delay was a main problem, that he could only speak one to two words, such as "give me", "I want". He also displayed some autistic behaviors, including occasionally repetitive hand movements, no eye-contact and no interest to others. Febrile seizures initially occurred at 8 months of age, then attacked 2-3 times per year. Seizure-free was achieved for 4 months with levetiracetam (LEV) and VPA. MRI at 4 years old revealed long $\mathrm{T}_{1}$ and $\mathrm{T}_{2}$ signal around bilateral ventricle, and a septum pellucidum cyst. EEG was normal at 4 years of age. A known pathogenic de novo mutation, c.766C > T, p.Arg256*, in $M E F 2 C$ was discovered.

The genetic data and clinical information from the five patients with $M E F 2 C$ mutations were summarized in Table 1.

\section{Discussion}

In this study, five $M E F 2 C$ mutations were identified in RTT (-like) syndrome or non-syndromic intellectual disability patients, of which three mutations were novel. The $M E F 2 C$ gene was originally identified as the phenocritical gene in the $5 \mathrm{q} 14.3$ microdeletion syndrome [5, 6]. Consecutively, intragenic deletions/insertions and 
Table 1 Clinical information of patients with MEF2C (NM_001193350) mutation

\begin{tabular}{|c|c|c|c|c|c|}
\hline $\mathrm{ID}$ & Patient 1 & Patient 2 & Patient 3 & Patient 4 & Patient 5 \\
\hline Sex & $\mathrm{F}$ & $\mathrm{F}$ & $\mathrm{F}$ & $M$ & M \\
\hline Mutation & c. $48 \mathrm{C}>\mathrm{G}$, p.Asn16Lys & c. $565 \mathrm{C}>\mathrm{T}, \mathrm{p} . \operatorname{Arg} 189^{*}$ & c.334G > T, p.Glu112* & c. $403-1 \mathrm{G}>\mathrm{T}$ & $\begin{array}{l}\text { c. } 766 C>T, \\
\text { p.Arg256* }\end{array}$ \\
\hline Origin & de novo & $\begin{array}{l}\text { mother WT; father } \\
\text { unknown }\end{array}$ & $\begin{array}{l}\text { father } W T ; \\
\text { mother unknown }\end{array}$ & de novo & de novo \\
\hline Age & $5 y 9 \mathrm{mo}$ & $2 \mathrm{y}, 6 \mathrm{mo}$ & $2 y 4 m o$ & $7 y 8 \mathrm{mo}$ & $6 y 4$ mo \\
\hline Sz (age of onset) & $Y(1 \mathrm{y} 10 \mathrm{mo})$ & N & $Y(9 \mathrm{mo})$ & $Y(1 \mathrm{y})$ & $Y(8 \mathrm{mo})$ \\
\hline Sz types & PS & - & FS & $F S, P S, S E$ & FS \\
\hline Response to AEDs & $\begin{array}{l}\text { Seizure free for } 4 \\
\text { months, with OXC, } \\
\text { VPA, TPM }\end{array}$ & - & - & $\begin{array}{l}\text { seizures free after } \\
4 \mathrm{y} \text {, with VPA }\end{array}$ & $\begin{array}{l}\text { seizures free } \\
6 y \text {, with LEV, VPA }\end{array}$ \\
\hline Motor development & $\begin{array}{l}\text { Head control }(8 \mathrm{mo}) \text {, } \\
\text { sit }(12 \text { mo), } \\
\text { cannot walk }\end{array}$ & $\begin{array}{l}\text { Head control }(5 \mathrm{mo}) \text {, } \\
\text { sit }(8 \mathrm{mo}) \text {, cannot } \\
\text { walk, head } \\
\text { circumstance } \\
48.5 \mathrm{~cm}(2 \mathrm{y})\end{array}$ & $\begin{array}{l}\text { Head control (2 mo), } \\
\text { sit }(12 \mathrm{mo}) \text {, walk } \\
(23 \mathrm{mo}) \text {, abnormal } \\
\text { gaits, head circumstance } \\
45.3 \mathrm{~cm}(2 \mathrm{y} 4 \mathrm{mo})\end{array}$ & $\begin{array}{l}\text { Head control (1y), sit } \\
\text { (1y } 2 \mathrm{mo}), \\
\text { walk (1 y, } 6 \mathrm{mo})\end{array}$ & $\begin{array}{l}\text { Head control } \\
(7 \mathrm{mo}) \text {, sit (1y), } \\
\text { walk (2y), head } \\
\text { circumstance } \\
52 \mathrm{~cm}(6 \mathrm{y} 4 \mathrm{mo})\end{array}$ \\
\hline Cognitive outcome & Severe ID & Severe ID & Severe ID & Severe ID & Severe ID \\
\hline Language & N & N & $\begin{array}{l}\text { Unmeaningful } \\
\text { murmur }\end{array}$ & $\mathrm{N}$ & 1 to 2 words \\
\hline Poor eye-contact & Y & Y & Y & Y & Y \\
\hline Repetitive behaviour & Y & Y & Y & Occassionlly & Occassionally \\
\hline Poor hand skills & Y & Y & Y & Normal & Normal \\
\hline Hypotonia & Y & Y & Y & N & N \\
\hline Family history & N & N & N & $\mathrm{N}$ & N \\
\hline EEG & $\begin{array}{l}\text { Sharp-slow waves } \\
\text { at right medial } \\
\text { and posterior temporal, } \\
\text { followed by } \\
\text { generalization } \\
(2 \mathrm{y}, 11 \mathrm{mo})\end{array}$ & NA & Normal $(2 y, 4 m o)$ & $\begin{array}{l}\text { Sharp-and-slow } \\
\text { waves around } \\
\text { Pz }(4 \mathrm{y}, 1 \mathrm{mo})\end{array}$ & Normal (4 y) \\
\hline MRI & $\begin{array}{l}\text { enlargement } \\
\text { of frontal } \\
\text { subarachnoid } \\
\text { space }(1 \mathrm{y})\end{array}$ & $\begin{array}{l}\text { Long } T_{1} \text { and } T_{2} \\
\text { signal at posterior } \\
\text { horn of bilateral } \\
\text { ventricle. }\end{array}$ & $\begin{array}{l}\text { Hypomyelination } \\
(1 \mathrm{y}, 10 \mathrm{mo})\end{array}$ & Normal (3y) & $\begin{array}{l}\text { Long } T_{1} \text { and } T_{2} \\
\text { signal around } \\
\text { bilateral ventricle, } \\
\text { septum pellucidum } \\
\text { cyst (4y) }\end{array}$ \\
\hline Other symptoms & hypalgesia & - & $\begin{array}{l}\text { Feeding difficulty, } \\
\text { sleeping disturbance, } \\
\text { irritability, recurrent } \\
\text { respiratory infection, } \\
\text { bruxism }\end{array}$ & $\begin{array}{l}\text { No interest } \\
\text { to others }\end{array}$ & $\begin{array}{l}\text { No interest } \\
\text { to others }\end{array}$ \\
\hline
\end{tabular}

F, female; M, male; Y, yes; N, no; NA, not avaliable; ID, intellectual disability; VPA, valproate; LEV, levetriacetam; OXC, oxcarbazepine; TPM, topiramate; y, year; mo, month; AEDs, antiepileptic drugs

point mutations of $M E F 2 C$ were discovered in patients with neurodevelopmental disorders, including intellectual disability and epilepsy [7]. As most patients were detected having multi-gene microdeletions involved $M E F 2 C$, the phenotype of $M E F 2 C$ gene mutation is not well recognized $[8,9]$. Up to now, only 14 point mutations in $M E F 2 C$ have been described in patients with neurological disorders [7, 10-13], including mutations discovered in this study, as is shown in Fig. 1. Our findings provide support for delineating the clinical features of patients with $M E F 2 C$ point mutations, as well as the genotype-phenotype relationship.

$M E F 2 C$ gene, located at $5 \mathrm{q} 14$, encodes myocyte enhancer-binding factor $2 \mathrm{C}$, a transcription factor that is indispensable in early neuroprogenitor development [2,
14]. The human $M E F 2 C$ protein consists five core structural domains, including MADS (MCM1, agamous, deficiens, serum response factor), myocyte enhancer factor 2 (MEF2), transcriptional activation domain 1 (TAD1), transcriptional activation domain 2 (TAD2), and nuclear localization signal (NLS) [15]. The MADS domain contains 56 amino acids, the MEF2 domain starts from amino acid 57 to 86 , and the HJURP-C domain consists of 30 amino acids, while the stereostructure of rest domians remains unknown. The main role of MADS domain and the adjacent $M E F 2 C$ domain is to mediate dimerization and DNA binding, whereas the rest domains act as the transcriptional activator [15]. The $M E F 2 C$ mutations are scattered through the whole $M E F 2 C$ protein, and there's no hot mutant region (Fig. 1). 
Typical clinical manifestations in patients with $M E F 2 C$ gene mutations encompass global developmental delay, intellectual disability, absent speech, poor eye-contact and various minor brain anomalies on MRI [11]. A subset of patients with $M E F 2 C$ haploinsufficiency phenotypically resembles RTT, including psychomotor stagnation, stereotypical behavior, poor hand skills, etc., $[4,7,16]$ Our findings basically coincided with previous description. All patients of our cohort presented with cognitive impairment, speech disorder, gross motor delay and lack of eye-contact. MRI was abnormal in four out of five patients, with diverse anomalies, including enlargement of frontal subarachnoid space, hypomyelination, abnormal signals at posterior horn of bilateral ventricle or bilateral ventricle. Among them, one female manifestated as classical RTT and other two females displayed RTT-like phenotype, whereas two males presented with non-syndromic ID.

The overwhelming majority of patients who had macro-deletions partially or entirely encompassing the $M E F 2 C$ gene, cannot walk independently. However, including 3 of our cases (patients 3-5), 7 (7/14, 50\%) patients with $M E F 2 C$ point mutations acquired the walking abilities [12, 17]. It indicates that $M E F 2 C$ point mutations might cause milder phenotypes than large intragenic deletions or completely deletions. Additionally, the phenotype of patient 4 (c.565C > T, p.Arg 189*) and patient 5 (c.766C > T, p.Arg 256") was milder than that of patient 1 (c. $48 \mathrm{C}>\mathrm{G}$, p.Asn16Lys), patient 2 (c.334G > T, p.Glu112*) and patient 3 (c.403-1G > T). As it was shown in Fig. 1, that the later three mutations located at the upstream, whereas the other two mutations located at the downstream of the $M E F 2 C$ protein, which suggested that the phenotypic severity may be associated with the mutation site.

Stereotypic behaviors, such as head rocking, hand-mouthing, hand clapping and wringing were reported in some patients with $M E F 2 C$ mutations [7]. In our cohort, repetitive hand movements were obvious in the three females, whereas it was just occassionally observed in two male cases. Meanwhile, the three females only had limited hand skills, while it was basically normal in both male patients. Besides, bruxism, breathing and sleeping disturbance were also presented in the three females of RTT (-like) cohort. The reason accounted for the different clinical feature in male and female patients with $M E F 2 C$ gene mutation need to be further studied.

More than half patients with $M E F 2 C$ haploinsufficiency experienced epilepsy [18]. Seizures generally arised during infancy or early childhood, which were commonly triggered by fever. Tonic-clonic seizures, myoclonic seizures were the most common seizure types, partial seizures, infantile spasms, atypical absence and febrile seizures were also described. Most epilepsy patients responded well to anti-epileptic drugs, whereas refractory in a few cases were also reported [18]. In this study, four $(4 / 5,80 \%)$ patients developed epilepsy within one year old. Febrile seizures were occurred in all of them, partial seizures were reported in two patients, and one patient had history of epileptic status. Seizure-free was achieved in all of them by mono- or multi-antiepileptic drugs (AEDs) therapy.

Mild to severe hypotonia was reported in most of the patients [12]. In our cohort, severe hypotonia was observed in three females. MRI showed nonspecific abnormalities in four of our patients, including hypomyelination, enlarged ventricles, abnormal signal on posterior horn of bilateral ventricle, just as that was reported in the literature [5].

Recently, $M E F 2 C$ mutations were founded in patients with heart disorders, including patent ductus arteriousus (PDA), double outlet right ventricle (DORV), ventricular septal defect (VSD) and dilated cardiomyopathy (DCM), accompanied with or without neurological symptoms [19-21]. All patients of our cohort had no medical history of heart diseases. As DCM is usually adult-onset, a longer term of ultrasonic cardiogram monitoring is necessary for patients with $M E F 2 C$ mutations. There was no relationship between the genotype and phenotype with or without heart disorders and/or neurological symptoms. The clinical heterogeneity might indicated the partly incomplete penetrance.

\section{Conclusions}

Our findings expanded the spectrum of point mutations of $M E F 2 C$ gene, and also showed some relationship between phenotype and $M E F 2 C$-genotype. The different clinical features in male and female patients with $M E F 2 C$ gene mutation need to be verified in a larger sample. $M E F 2 C$ gene mutational analysis was recommended in patients with ID, especially in the RTT (-like) cohort without mutations in traditional RTT genes (MECP2, CDKL5, FOXG1) .

\section{Additional file}

Additional file 1: Table S1. List of 512 candidate genes. (DOCX 20 kb)

\section{Abbreviations}

AEDs: antiepileptic drugs; DCM: dilated cardiomyopathy; DORV: double outlet right ventricle; EEG: electroencephalogram; ID: intellectual disability;

LEV: levetiracetam; NGS: next-generation sequencing; OXC: oxcarbazepine; PDA: patent ductus arteriousus; TPM: topiramate; VPA: valproate;

VSD: ventricular septal defect

\section{Acknowledgements}

We would like to thank the patients and their family for their cooperation in this study

\section{Funding}

The study was funded by 985 Peking University and Clinical Hospital Cooperation Project (2013-1-06), Clinical Research Special Fund of Wu Jieping Medical Foundation (320.6750.17091), and Technology Innovation Talents Special Fund of Harbin Science and Technology Bureau

(2016RAXYJ089) 


\section{Availability of data and materials}

Raw exome data and associated variant calls will not be shared, as part of our work has not been published.

\section{Authors' contributions}

$X H B, X R W$, and SJY obtained the funding and designed the research. QPZ, $Y C$ and YXW acquired clinical data and samples from the patients. QPZ also made contribution in the analysis of NGS data. YC and YXW also provided help in clinical evaluation of the patients. JPW validated the parental origin of candidate variants by PCR-Sanger sequencing, made routine follow-up of the patients and drew up the manuscript. XRW also made contribution in English editing of the manuscript. All the authors have read and approved the manuscript and ensure that this is the case.

\section{Ethics approval and consent to participate}

This study was approved by the Medical Ethics Committee, Peking University First Hospital. Guardians of all participants have signed the informed consent.

\section{Consent for publication}

Consent for publication was obtained from the parents of the patients. All the guardians consented to publish the medical information of the patients.

\section{Competing interests}

The authors declare that they have no competing interests.

\section{Publisher's Note}

Springer Nature remains neutral with regard to jurisdictional claims in published maps and institutional affiliations.

\section{Author details}

'Department of Pediatrics, Peking University First Hospital, No 1, Xi'anmen Street, Xicheng District, Beijing 100034, China. ${ }^{2}$ Department of neurology, Harbin children's hospital, Harbin 150010, Heilongjiang Province, China.

Received: 23 May 2018 Accepted: 26 September 2018

Published online: 30 October 2018

\section{References}

1. Potthoff MJ, Olson EN. MEF2C: a central regulator of diverse developmental programs. Development. 2007;134(23):4131-40.

2. Leifer D, Krainc D, Yu YT, McDermott J, Breitbart RE, Heng J, et al. MEF2C, a MADS/MEF2-family transcription factor expressed in a laminar distribution in cerebral cortex. Proc Natl Acad Sci U S A. 1993;90(4):1546-50

3. Li H, Radford JC, Ragusa MJ, Shea KL, McKercher SR, Zaremba JD, et al. Transcription factor MEF2C influences neural stem/progenitor cell differentiation and maturation in vivo. Proc Natl Acad Sci U S A. 2008; 105(27):9397-402.

4. Zweier M, Rauch A. The MEF2C-related and $5 q 14.3 q 15$ microdeletion syndrome. Mol Syndromol. 2012;2(3-5):164-70.

5. Hotz A, Hellenbroich Y, Sperner J, Linder-Lucht M, Tacke U, Walter C, et al. Microdeletion 5q14.3 and anomalies of brain development. Am J Med Genet A. 2013;161A(9):2124-33.

6. Cardoso C, Boys A, Parrini E, Mignon-Ravix C, McMahon JM, Khantane S, et al. Periventricular heterotopia, intellectual disability, and epilepsy associated with 5q14.3-q15 deletion. Neurology. 2009;72(9):784-92.

7. Le Meur NH-EM, Jaillard S, Goldenberg A, Joriot S, Amati-Bonneau P, Guichet A, Barth M, Charollais A, Journel H, Auvin S, Boucher C, Kerckaert JP, David V, Manouvrier-Hanu S, Saugier-Veber P. Frébourg T, Dubourg C, Andrieux J, Bonneau D. MEF2C haploinsufficiency caused by either microdeletion of the $5 \mathrm{q} 14.3$ region or mutation is responsible for severe intellectual disability with stereotypic movements, epilepsy and/or cerebral malformations. J Med Genet. 2010:47(1):22-9.

8. Nowakowska BA, Obersztyn E, Szymanska K, Bekiesinska-Figatowska M, Xia Z, Ricks CB, et al. Severe intellectual disability, seizures, and hypotonia due to deletions of MEF2C. Am J Med Genet B Neuropsychiatr Genet. 2010; 153B(5):1042-51.

9. Engels H, Wohlleber E, Zink A, Hoyer J, Ludwig KU, Brockschmidt FF, et al. A novel microdeletion syndrome involving 5q14.3-q15: clinical and molecular cytogenetic characterization of three patients. Eur J Hum Genet. 2009; 17(12):1592-9.
10. Zweier M, Gregor A, Zweier C, Engels $H$, Sticht $H$, Wohlleber E, et al. Mutations in MEF2C from the $5 q 14.3 q 15$ microdeletion syndrome region are a frequent cause of severe intellectual disability and diminish MECP2 and CDKL5 expression. Hum Mutat. 2010;31(6):722-33.

11. Bienvenu T, Diebold B, Chelly J, Isidor B. Refining the phenotype associated with MEF2C point mutations. Neurogenetics. 2013;14(1):71-5.

12. Vrečar IIJ, Jones EA, Kingston H, Reardon W, Kerr B, Clayton-Smith J, Douzgou S. Further clinical delineation of the MEF2C Haploinsufficiency syndrome: report on new cases and literature review of severe neurodevelopmental disorders presenting with seizures, absent speech, and involuntary movements. J Pediatr Genet. 2017:6(3):129-41.

13. Srivastava S, Cohen JS, Vernon H, Baranano K, McClellan R, Jamal L, et al. Clinical whole exome sequencing in child neurology practice. Ann Neurol. 2014;76(4):473-83

14. Cesaretti C, Spaccini L, Righini A, Parazzini C, Conte G, Crosti F, et al. Prenatal detection of 5 q14.3 duplication including MEF $2 \mathrm{C}$ and brain phenotype. Am J Med Genet A. 2016;170A(5):1352-7.

15. Dong C, Yang XZ, Zhang CY, Liu YY, Zhou RB, Cheng QD, et al. Myocyte enhancer factor $2 \mathrm{C}$ and its directly-interacting proteins: a review. Prog Biophys Mol Biol. 2017;126:22-30.

16. Lambert L, Bienvenu T, Allou L, Valduga M, Echenne B, Diebold B, et al. MEF2C mutations are a rare cause of Rett or severe Rett-like encephalopathies. Clin Genet. 2012;82(5):499-501.

17. Rocha H, Sampaio M, Rocha R, Fernandes S, Leao M. MEF2C haploinsufficiency syndrome: report of a new MEF2C mutation and review. Eur J Med Genet. 2016;59(9):478-82.

18. Paciorkowski ARTR, Rosenfeld JA, Hoover JM, Harris CJ, Winter S, Lacassie Y, Bialer M, Lamb AN, Schultz RA, Berry-Kravis E, Porter BE, Falk M, Venkat A, Vanzo RJ, Cohen JS, Fatemi A, Dobyns WB, Shaffer LG, Ballif BC, Marsh ED. MEF2C haploinsufficiency features consistent hyperkinesis, variable epilepsy, and has a role in dorsal and ventral neuronal development pathways. Neurogenetics. 2013;14(2):99-111.

19. Yuan F, Qiu ZH, Wang XH, Sun YM, Wang J, Li RG, et al. MEF2C loss-offunction mutation associated with familial dilated cardiomyopathy. Clin Chem Lab Med. 2018:56(3):502-11.

20. Qiao XH, Wang F, Zhang XL, Huang RT, Xue S, Wang J, et al. MEF2C loss-offunction mutation contributes to congenital heart defects. Int J Med Sci. 2017;14(11):1143-53.

21. Lu CX, Wang W, Wang Q, Liu XY, Yang YQ. A novel MEF2C loss-of-function mutation associated with congenital double outlet right ventricle. Pediatr Cardiol. 2018

Ready to submit your research? Choose BMC and benefit from:

- fast, convenient online submission

- thorough peer review by experienced researchers in your field

- rapid publication on acceptance

- support for research data, including large and complex data types

- gold Open Access which fosters wider collaboration and increased citations

- maximum visibility for your research: over $100 \mathrm{M}$ website views per year

At $\mathrm{BMC}$, research is always in progress.

Learn more biomedcentral.com/submissions 